\title{
Can Urinary Catheterization Before Birth Reduce Postpartum Urinary Retention?
}

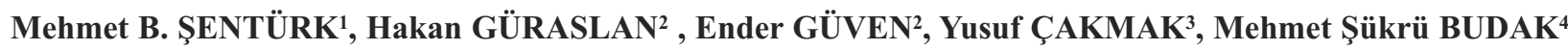 \\ Istanbul, Turkey
}

\section{ABSTRACT}

OBJECTIVE: Postpartum urinary retention (PUR) is defined as no spontaneous micturition in a period of more than 6 hours postpartum or residual volume of $>150 \mathrm{cc}$ after urination. If a diagnosis is not made, there may be problems of over-distention of the bladder and consequently, denervation, detrusor atony and long-term micturition problems. This study aimed to examine the effect of urinary catheterization during birth on postpartum urinary retention (PUR).

STUDY DESIGN: A prospective randomized study was conducted with 137 patients. The study and control groups were formed according to a random number table. In the study group, urinary catheterization was applied before birth. In both groups, the time of the first postpartum micturition was recorded and after the first micturition, the residual urine volume was measured with catheterization. Cases with no spontaneous micturition in the first 6 hours postpartum were accepted as PUR. The two groups were compared with respect to time of first micturition and residual urine volume using Mann Whitney U-test and the presence of PUR with Chi-square test.

RESULTS: The time to first micturition was determined to be shorter in the group where urinary catheterization was applied before birth, the PUR rate was lower and the amount of residual urine was less $(p<0.05)$. Birthweight, duration of labour, maternal age, weight, gravida and use of oxytocin were similar between the groups $(p>0.05)$.

CONCLUSION: Urinary catheterization before birth reduces the rate of PUR.

Keywords: Birth, Micturition, Residual Volume, Urinary catheterizations

Gynecol Obstet Reprod Med 2016;22:17-21

\section{Introduction}

Postpartum urinary retention (PUR) is defined as non-full urination following birth. Overt PUR is defined as no spontaneous micturition for a period of more than 6 hours postpartum, while covert PUR is defined as a residual volume of $>150$ cc after urination. ${ }^{1,2}$ The incidence varies over a wide range of $0.05 \%-37 \% .^{2}$ PUR can cause over-distention of the bladder and consequently, denervation, detrusor atony and

${ }^{1}$ Department of Obstetrics and Gynecology Zeynep Kamil Gynecologic and Pediatric Training and Research Hospital, Istanbul.

${ }^{2}$ Departments of Obstetrics and Gynecology, Bakirköy Dr. Sadi Konuk Teaching and Research Hospital, Istanbul.

${ }^{3}$ Departments of Obstetrics and Gynecology Batman State Hospital, Batman.

${ }^{4}$ Departments of Obstetrics and Gynecology Diyarbaktr Women and Child Hospital, Diyarbakır.

Address of Correspondence: Mehmet B. Şentürk

Department of Obstetrics and

Gynecology Zeynep Kamil Gynecologic and Pediatric Training and Research

Hospital Üsküdar Istanbul, Turkey

dr.baki77@gmail.com

Submitted for Publication:

03.02 .2016

Accepted for Publication: long-term micturition problems. ${ }^{3}$ Although the pathophysiology of PUR is not fully known, physiological, neurological and mechanical reasons in the postpartum period may be responsible. ${ }^{4}$ Method of birth, analgesia and anesthesia methods, duration of labour, perineal trauma, birthweight, parity, maternal age, weight and postpartum post-void residual volume may be responsible factors. ${ }^{2}$ Care of the bladder either immediately prior to or during delivery to encourage micturition of the pregnant patient during labour may reduce PUR besides reducing the effect of these factors.

The aim of this study was to investigate the effect on PUR of temporary urinary catheterization applied immediately before birth.

\section{Material and Method}

This prospective, randomized study was conducted at the Bakirkoy Training and Research Hospital between $1{ }^{\text {st }}$ January and $30^{\text {th }}$ September 2014. Approval for the study was granted by the Local Ethics Committee with decision no 2014/04/07. Informed consent was obtained from all study participants.

The study included 137 patients giving birth by the vaginal route. Patients with pelvic organ prolapse, a history of vaginal or bladder surgery, a history of bladder atony or over- 
active bladder and those with urinary system infection were excluded. In addition, those requiring catheterization because of acute bladder distention or palpable bladder were excluded. To be able to more objectively evaluate the effect of catheterization alone, cases with opened episiotomy, serious perineal injury, birthweight of the infant of $>4000 \mathrm{gr}$ and those to whom fundal pressure was applied, were also excluded.

On first admittance to the hospital, all patients were examined with respect to gravida, age, weight, systemic diseases, vaginal examination and full urine examination for the diagnosis of urinary system infection. A standard $1000 \mathrm{cc}$ of saline was given to all patients and 20 units of oxytoycin was added in saline if induction was required.

During labour, the duration of the active phase, $2^{\text {nd }}$ and $3^{\text {rd }}$ stage were recorded. The cases who were to have catheterization applied before birth and those who were not were determined by a random number table. Those who were not to have catheterization were defined as the control group. In the study group, catheterization was applied at the end of the $2^{\text {nd }}$ stage before labour of the head. In the postpartum follow-up, the time of the first urination was recorded, then the residual volume was measured with catheterization. When there was no urination in the first 6 hours postpartum, those cases were accepted as PUR. ${ }^{1}$ The rates of PUR were compared between the study and control groups and the cases with and without PUR were compared with each other.

Statistical evaluation of the data was done with SPSS for Windows v. 11.5 software. In the study and the control group, comparison was made of age, weight and infant birthweight with Student's t-test, gravida, duration of delivery phases, time to urination and postvoidal residual amount with Mann Whitney U-test and the rates of oxytocin application with Chisquare test. In cases with and without PUR, comparison of infant birthweight was made with t-test and the oxytocin and du- ration of labour phases, time to first urination, volume before or after birth and residual amount after first urination with Mann Whitney U-test. A value of $p<0.05$ was accepted as statistically significant. In our study, it is assuming there may be a difference of \pm 15 units; The strength test $90 \%$ and when the type I error is received as 0.05 , the sample size was calculated to be at least 120 individuals.

\section{Results}

The mean age of all the pregnant patients in the study was 29.56 years, mean weight was $70.71 \mathrm{~kg}$ and mean gravida was 2. Labour was facilitated with oxytocin in 40 (29.2\%) cases. The mean birthweight of the infants was $3435 \mathrm{gr}$ (Table 1). The durations of the stages of labour, the time to first micturition and PUR rates are shown in Table 1. PUR was determined in $34(24.8 \%)$ cases. No statistically significant difference was seen between the study and control groups with respect to age,

Table 1: Patient characteristics, time of labor

\begin{tabular}{ll}
\hline Age (Mean \pm SD) year & $29.56 \pm 6.24$ \\
Weight (Mean \pm SD) kg & $70.71 \pm 11.36$ \\
Gravida (median (min.-max.)) & $2(1-7)$ \\
Oxytocin use $\mathrm{n}(\%)$ & $40(29.2 \%)$ \\
Infant Weight (ort $\pm S D$ ) gr & $3435 \pm 2802$ \\
$\begin{array}{l}\text { Active phase duration } \\
\text { (Mean } \pm S D \text { (median)) min }\end{array}$ & $212 \pm 146(180)$ \\
Second stage duration of labor & $17.64 \pm 15.05(10.0)$ \\
(Mean $\pm S D$ (median)) min & \\
Third stage duration of labor & $6.29 \pm 3.72(5.0)$ \\
(Mean $\pm S D$ (median)) min & \\
Total labor time & $235.90 \pm 150.39(210.0)$ \\
(Mean $\pm S D$ (median)) min & \\
Micturition (Mean $\pm S D)$ min & $364.53 \pm 947.78(270.0)$ \\
PUR $\mathrm{n}(\%)$ & $34(24.8 \%)$ \\
\hline
\end{tabular}

Pur: Postpartum urinary retention

Table 2: Comparison of catheterized and non-catheterized cases

\begin{tabular}{|c|c|c|c|}
\hline & \multicolumn{2}{|l|}{ Catheterization } & \multirow[t]{2}{*}{$\mathrm{P}$} \\
\hline & No $(n=68)$ & Yes $(n=69)$ & \\
\hline Age (Mean $\pm S D)$ year & $29.66 \pm 6.47$ & $29.46 \pm 6.06$ & $0.854^{a}$ \\
\hline Weight (Mean $\pm S D)$ kg & $70.63 \pm 11.12$ & $70.77 \pm 11.66$ & $0.945^{\mathrm{a}}$ \\
\hline Gravida (median(min.-max.)) & $2(1-7)$ & $2(1-6)$ & $0.873^{\mathrm{b}}$ \\
\hline Oxytocin use $n(\%)$ & $22(32.4)$ & $18(26.1)$ & $0.420^{c}$ \\
\hline Infant Weight (Mean \pm SD) gr & $3682.9 \pm 3954.4$ & $3191.3 \pm 420.9$ & $0.306^{a}$ \\
\hline Active phase duration of labor (Mean $\pm \mathrm{SD}$ (median)) $\min$ & $230 \pm 150(205)$ & $194 \pm 142(180)$ & $0.087^{\mathrm{b}}$ \\
\hline Second stage duration of labor (Mean $\pm S D($ median $)$ ) min & $16.88 \pm 15.16(10.0)$ & $18.39 \pm 10.01(15.0)$ & $0.480^{\mathrm{b}}$ \\
\hline Third stage duration of labor (Mean $\pm S D($ median)) min & $6.94 \pm 4.31(5.0)$ & $5.65 \pm 2.91(5.00)$ & $0.130^{\mathrm{b}}$ \\
\hline Total labor time (Mean $\pm \mathrm{SD}($ median $))$ min & $254.01 \pm 153.38(226.50)$ & $218.04 \pm 146.30(188.00)$ & $0.119^{b}$ \\
\hline Postpartum micturition time (ort $\pm S D($ median$)$ ) min & $498.82 \pm 1331.72(312.50)$ & $232.17 \pm 115.70(210.00)$ & $0.001^{\mathrm{b}}$ \\
\hline PUR n(\%) & $28(41.2)$ & $6(8.7)$ & $0.001^{c}$ \\
\hline Postvoidal residual volume (Mean $\pm \mathrm{SD}$ (median)) cc & $77.27 \pm 82.06(50.00)$ & $19.42 \pm 43.88(0.00)$ & $0.001^{\mathrm{b}}$ \\
\hline
\end{tabular}

a: $t$ test for independent samples, b: Mann-Whitney $U$ test, c: Chi-Square test, SD: Standard deviation, PUR: Postpartum urinary retention 
weight, gravida, use of oxytocin, infant birthweight and duration of labour ( $>>0.05$ ) (Table 2$)$. In the group where catheterization was not applied before birth, the time to first micturition was longer, the rate of PUR was higher and the residual volume after the first micturition was seen to be greater $(p<0.05)$ (Table 2). When the cases were compared according to the presence of PUR, the time to first micturition and the residual volume after first micturition were seen to be greater in cases with PUR $(p<0.05)$. No statistically significant difference was determined with respect to stages of labour, infant birthweight and oxytocin application ( $>>0.05$ ) (Table 3 ). In all cases with PUR, spontaneous recovery was seen within the first 48 hours.

\section{Discussion}

The results of this study showed lower rates of PUR in patients with urinary catheterization applied immediately before the end of the $2^{\text {nd }}$ stage of labour. The residual volume after first urination was also found to be lower in the cases with catheterization.

Through inhibition of the detrusor muscle with the effect of increased progesterone during pregnancy, there may be retention for hours or even days after birth. ${ }^{5}$ Bladder sensitivity and these reductions in tonus are more evident after vaginal route delivery in particular. ${ }^{6,7}$ After vaginal delivery, the bladder is more flacid, less hypotonic and less sensitive for full voiding. ${ }^{5}$

The clear causes of PUR are still not known. ${ }^{4}$ A series of physiological, neurological and mechanical reasons in the postpartum period may be responsible for PUR. ${ }^{4}$ Especially when the $1^{\text {st }}$ and $2^{\text {nd }}$ stages of labour are prolonged, neurological damage may cause PUR. ${ }^{4}$ The pudendal and pelvic nerves may be damaged by impingement made by the infant's head in prolonged labour. ${ }^{8}$ This damage to the nerves affects the parasympathetic pathway, which is responsible for providing normal micturition. ${ }^{8}$ In addition, this damage can cause urinary incontinence in the postpartum period. ${ }^{8}$ Mechanically, an overdistended bladder related to prolonged labour has a negative effect on the contraction ability of the bladder.6,-12 The pain of edema and injuries to the perineal tissues associated with prolonged labour may cause problems initiating micturition. ${ }^{8,11,13}$

In the literature it has been reported that infant birthweight of $>3800$ gr causes PUR. ${ }^{4}$ In the current study, the mean birthweight in the group with PUR was 3243.23 gr and in the group without PUR, it was 3498.72 gr ( $p>0.05)$. The size of the sample can be considered insufficient to evaluate the effect of fetal weight on PUR. Cases with an infant $>4000$ gr birthweight were not included in the study. However, as there was no effect of fetal weight on PUR, it was possible to make a more objective evaluation of the factor of catheterization only.

The duration of the stages of labour may contribute to the development of PUR. In a study by Kekre et al., ${ }^{14}$ the duration of labour in cases with PUR was found to be longer and a cutoff value of 700 mins was reported. Similarly, Yip et al. ${ }^{8}$ reported higher rates of PUR in cases with labour lasting longer than 800 mins. There are studies that state that only a prolongation of the $2^{\text {nd }}$ stage of labour causes PUR. ${ }^{15}$ In a prolonged $2^{\text {nd }}$ stage of labour, the extended duration of pressure on the bladder by the infant's head and pressure on the pelvic muscles may cause damage to both the pelvic nerve and muscles, and with this cause a reduction of detrusor sensitivity and motor function in the postpartum period. There may be an additional problem of starting or effectively maintaining micturition because of the effect on the ureter. ${ }^{15}$ In the current study, labour was not as prolonged as in the above-mentioned studies. The two groups with and without PUR were evaluated in three stages: the active phase, stage 2 and stage 3 and the values were found to be similar for the three groups separately and for the total duration of labour in both groups $(\mathrm{p}>0.05)$. That there was no effect on PUR of the duration of labour could have been due to the low number of cases in the sample.

Cases with perineal damage or opened episiotomy were

Table 3: Comparison of women with PUR and without PUR

\begin{tabular}{|c|c|c|c|}
\hline & \multicolumn{2}{|l|}{ PUR } & \multirow[t]{2}{*}{$\mathrm{P}$} \\
\hline & No $(n=103)$ & Yes $(n=34)$ & \\
\hline Oxytocin use $n(\%)$ & $28(27.2 \%)$ & $12(35.3 \%)$ & $0.367 c$ \\
\hline Infant Weight (Mean \pm SD) gr & $3498.72 \pm 3222.28$ & $3243.23 \pm 469.98$ & $0.647 a$ \\
\hline Active phase duration of labor (Mean $\pm S D$ (median)) min & $205.62 \pm 147.74(180.0)$ & $231.44 \pm 142.54(225.0)$ & $0.222 b$ \\
\hline Second stage duration of labor (Mean $\pm \mathrm{SD}$ (median)) min & $17.46 \pm 14.56(10.00)$ & $18.21 \pm 16.67(10.00)$ & $0.817 b$ \\
\hline Third stage duration of labor (Mean $\pm S D($ median)) min & $6.10 \pm 3.62(5.00)$ & $6.88 \pm 3.99(5.00)$ & $0.249 \mathrm{~b}$ \\
\hline Total labor time (Mean $\pm S D($ median $))$ min & $228.98 \pm 151.35(210.0)$ & $256.85 \pm 147.68(252.5)$ & $0.215 b$ \\
\hline Postvoidal residual volume (Mean $\pm \mathrm{SD}$ (median)) cc & $177.62 \pm 132.11(150.0)$ & $116.67 \pm 143.96(80.0)$ & $0.109 b$ \\
\hline Postpartum micturition time (ort $\pm S D($ median $)$ ) min & $214.95 \pm 92.01(210.0)$ & $817.65 \pm 1842.4(480.0)$ & $0.001 b$ \\
\hline Postvoidal residual volume (Mean $\pm \mathrm{SD}$ (median)) cc & $21.46 \pm 38.73(0.00)$ & $128.97 \pm 86.73(115.0)$ & $0.001 b$ \\
\hline
\end{tabular}

a: $t$ test for independent samples, $b$ : Mann-Whitney U test, $c$ : Chi-Square test, PUR: Postpartum Urinary Retention 
not included in this study as the aim was to more objectively evaluate the effect of catheterization on the development of PUR rather than perineal damage. Several studies have shown a relationship between perineal damage and PUR..$^{8,10,11,16,17}$ It has been reported that while there is no relationship between the degree of perineal damage and PUR, it is sufficient for there to be an increase in PUR incidence. ${ }^{18}$ Perineal damage may cause PUR because of edema in the tissues or by directly affecting the detrusor tissue. In addition, pain reflex associated with perineal damage causing ureteral spasm may play a role in the development of PUR. ${ }^{14}$

Several complications of PUR have been described in the literature. Short-term complications are seen to be interruption of urine flow, hesitation, poor flow and overflow incontinence with stress because of pain and discomfort. ${ }^{19}$ Although there are no clear data on long-term complications, frequency, a feeling of tiredness on urination, stress urinary incontinence and detrusor instability have been reported with persistence of PUR. ${ }^{14}$ In a study by Andolf et al., ${ }^{20}$ cases with PUR were followed up for 3-4 years and no difference was reported in the prevalence of urinary symptoms from the normal population. In a large series study, PUR persistence was reported at $0.05 \%$ and it was emphasized that this could be related to long-term bladder dysfunction. ${ }^{21}$ In another study, this rate was found to be $2.6 \% .{ }^{22}$ In most studies, it has been reported that retention recovers in a short time. ${ }^{14}$ Yip et al. ${ }^{8}$ reported that $82 \%$ of covert PUR cases recovered spontaneously within 4 days. In the current study, all cases achieved pain-free spontaneous urination within the first 48 hours.

The rate of PUR in the current study was seen to be $34.8 \%$. Various rates have been reported in the literature. Kekre et al. 14 evaluated 771 cases and reported a rate of $10.6 \%$, Buchanan and Beckmann ${ }^{2}$ reported $5.1 \%$ and other studies have published rates of $0.06 \%, 29.4 \%, 47 \%$ and $8.1 \% .^{7-9}$ These differences would seem to be due to different designs of the studies and whether the research was of overt or covert retention. In large series studies the prevalence is low. Kekre et al. ${ }^{14}$ accepted diagnostic criteria of postvoidal residual volume $>150 \mathrm{cc}$ (covert retention) and included all normal and instrumental deliveries in the studies. However, those studies were retrospective. ${ }^{2,23}$ Mulder et al. ${ }^{1}$ excluded cases of twin pregnancies and epidural analgesia as these were factors that could increase the PUR rate and the rate of covert retention was reported as $47 \%$.

In the current study, a Foley catheter was used for the measurement of residual volume. The use of ultrasonography to measure postvoidal residual volume is superior to catheterization with respect to not causing infection and not being traumatic. ${ }^{5}$ However, there is no universal opinion on the measurement of postvoidal residual volume. ${ }^{5}$ In studies that have compared ultrasonography and catheterization for the diagnosis of PUR, although no difference has been seen, some authors have reported that especially immediately after delivery the use of ultrasonography is not reliable due to the dimensions of the uterus. ${ }^{4,20,24,25}$

A limitation of the current study was the small number of cases. However, the effects of factors such as macrosomia, fundal pressure, twin pregnancies, prolonged labour, caesarean delivery and perineal damage were eliminated. Therefore, to what extent PUR was affected by the volume remaining in the bladder before delivery, and the voiding of that volume, can be considered to have been evaluated more objectively. In this respect, this study can be considered to be of value.

\section{Conclusion}

During vaginal birth, pelvic care is important. Throughout labour, when the levator ani muscle, the anal sphincter, detrusor muscle, urethral sphincter, pudendal and other pelvic nerves remain under pressure from the vaginal canal, there is a risk of ischemia, injury and denervation. This may entail short or long-term fecal or urinary incontinence, micturition difficulties, impaired sexual functions and prolapse, which then result in a decrease in quality of life, psychiatric problems and subsequent financial costs. Therefore, there is a need for obstetricians to undertake more research on this subject for less damage to be seen in pelvic tissue and organs during vaginal birth and for the application of proven methods. Despite the low number of cases in this study, the application of bladder catheterization immediately before the delivery of the infant's head was seen to decrease the rate of PUR and made a positive contribution to bladder care during birth.

\section{References}

1. Mulder FE, Rengerink KO, Van Der Post JA, Hakvoort RA, Roovers JW. Delivery-related risk factors for covert postpartum urinary retention after vaginal delivery. Int Urogynecol J. 2015;30. [Epub ahead of print].

2. Buchanan J, Beckmann M. Postpartum voiding dysfunction: identifying the risk factors. Aust N Z J Obstet Gynaecol 2014;54:41-5

3. Zaki MM, Pandit M, Jackson S. National survey for intrapartum and postpartum bladder care: assessing the need for guidelines. BJOG1112004;111:874-6.

4. Lim JL. Post-partum voiding dysfunction and urinary retention. Aust N Z J Obstet Gynaecol 2010;50:502-5.

5. Ajenifuja KO, Oyetunji IO, Orji EO, et al. Post-partum urinary retention in a teaching hospital in southwestern Nigeria. J Obstet Gynaecol Res.2013;39:1308-13

6. Hinman F. Postoperative overdistension of the bladder. Surg Gynecol Obstet 1976;45:901-2.

7. Page G, Buntinx F, Hanssens M. Indwelling bladder catheterization as part of postoperative care for caesarean 
section. The Cochrane Library 2003; Oxford, Update Software.

8. Yip SK, Brieger G, Hin LY, Chung T. Urinary retention in the post-partum period. The relationship between obstetric factors and the post-partum post-void residual bladder volume. Acta Obstet Gynecol Scand 1997;76:667-72.

9. Groutz A, Hadi E, Wolf Y. et al. Early postpartum voiding dysfunction: incidence and correlation with obstetric parameters. J Reprod Med 2004;49:960-4.

10. Carley ME, Carley JM, Vasdev G et al. Factors that are associated with clinically overt postpartum urinary retention after vaginal delivery. Am J Obstet Gynecol 2002;187: 430-3.

11. Groutz A, Gordon D, Wolman I, Jaffa A, Kupferminc MJ, Lessing JB. Persistent postpartum urinary retention in contemporary obstetric practice. Definition, prevalence and clinical implications. J Reprod Med 2001;46:44-8.

12. Mayo ME, Lloyd-Davies RW, Shuttleworth KE, Tighe JR. The damaged human detrusor: functional and electron microscopic changes in disease. Br J Urol 1973;45:116-25.

13. Teo R, Punter J, Abrams K, Mayne C, Tincello D. Clinically overt postpartum urinary retention after vaginal delivery: a retrospective case-control study. Int Urogynecol J Pelvic Floor Dysfunct 2007;18:521-24.

14. Kekre AN, Vijayanand S, Dasgupta R, Kekre N. Postpartum urinary retention after vaginal delivery. Int $\mathrm{J}$ Gynaecol Obstet 2011;112:112-5

15. Cavkaytar S, Kokanalı MK, Baylas A, Topçu HO, Laleli B, Taşçı Y. Postpartum urinary retention after vaginal delivery: Assessment of risk factors in a case-control study. J Turk Ger Gynecol Assoc 2014;15:140-3

16. Musselwhite KL, Faris P, Moore K, Berci D, King KM. Use of epidural anesthesia and the risk of acute postpartum urinary retention. Am J Obstet Gynecol 2007;196: 472.e1-472

17. Glavind K, Bjork J. Incidence and treatment of urinary retention postpartum. Int Urogynecol J 2003;14:119-121

18. Carroli G, Belizan J. Episiotomy for vaginal birth. Cochrane Database Syst Rev 1999;(3):CD000081. doi: 10.1002/14651858. CD000081

19. Ramsay IN, Torbet TE. Incidence of abnormal voiding parameters in the immediate postpartum period. Neurourol Urodyn 1993;12:179-83

20. Andolf E, Iosif CS, Jorgensen C, Rydhstrom H. Insidious urinary retention after vaginal delivery: prevalence and symptoms at follow up in a population based study. Gynecol Obstet Invest 1994;38:51-3.

21. Groutz A, Hasson J, Gold R, Pauzner D, Lessing J, Gordon D. Persistent postpartum urinary retention: prevalence, obstetric risk factors and management. J Urol 2008; 179:472

22. Ching-Chung L, Shuenn-Dhy C, Ling-Hong T, Ching C, Chao-Lun C, Po-Jen C. Postpartum urinary retention: assessment of contributory factors and long term clinical impact. Aust NZ J Obstet Gynecol 2002;42:365-8.

23. Humburg J, Troeger C, Holzgreve W, Hoesli I. Risk factors in prolonged postpartum urinary retention: an analysis of six cases. Arch Gynecol Obstet 2011;283:179-83.

24. Yip SK, Sahota D, Chang A. Determining the reliability of ultrasound measurements and the validity of the formulae for ultrasound estimation of postvoid residual bladder volume in postpartum women. Neurourol Urodyn 2003; 22:255-60.

25. Demaria F, Amar N. Prospective 3D ultrasonographic evaluation of immediate postpartum urinary retention volume in 100 women who delivered vaginally. Int Urogynecol J Pelvic Floor Dysfunct 2004;15:281-5. 